\title{
Robert Hooke's Micrographia of 1665 and 1667
}

\begin{abstract}
Until recently Robert Hooke's name was not widely known to the public. When he was remembered it was usually in connection with memories, often vague, of 'Hooke's Law' (the extension of an elastic body is proportional to the force applied to extend it). However, little or nothing was remembered of Hooke's connections with Robert Boyle, Christopher Wren and, later, Isaac Newton and others of that exalted circle, particularly John Wilkins who probably introduced him into it, of his long service to the Royal Society's regular programme of demonstrations, of his contributions to the theories of light and, indeed, of gravitation, of his surveying of London after the Great Fire of 1666 and his overseeing of much of its reconstruction. With new biographies of Hooke and television programmes about him, he is becoming quite widely recognised as
\end{abstract}

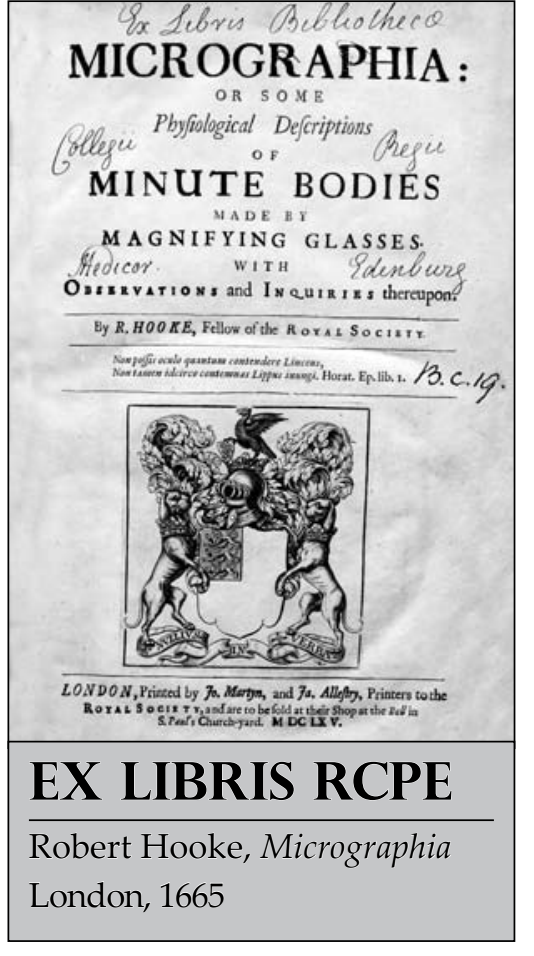

more important than Hooke's own observations using microscopy. Later, Hooke himself learned Dutch so that he could read Leeuwenhoek's letters.

However, while Leeuwenhoek's descriptions of his findings were lively and detailed, the sketches he provided were fairly crude. Hooke, on the other hand, devised a method of looking at a sheet of paper with one eye while observing through the microscope with the other so that he could trace the outlines of the virtual image seen by the microscope eye on the paper. He describes doing this to allow him to measure the magnification achieved by his instruments. He then worked up these sketches into illustrations which were engraved on copper plates to print the striking images that illustrate the Micrographia. probably the greatest seventeenth-century polymath, but even now the book in which his experimental work is most attractively presented is not well known, except by historians of science.

Hooke's Micrographia of 1665 and 1667, published by order of the Royal Society, is one of the remarkable works of early experimental science and one which exerted much influence in its time. When it is mentioned in popular articles now it is usually because it contains the first enlarged pictures of the louse and the head and eye of the housefly; in accounts intended for the professions the striking image of the first recognised microscopic fungus, mucor, and its spores is often shown. Hooke's description of what he named cells in the structure of cork is also well known. All of these observations and illustrations are, of course, perfectly genuine 'firsts'.

In the seventeenth century Micrographia seems to have acted as a stimulant to others interested in exploring what insights the newly invented microscopes offered into the world of objects too small to be seen clearly, or to be seen at all, by the unaided eye. It now seems to be established that the self-taught Dutch microscopist Antoni van Leeuwenhoek saw Hooke's Micrographia and probably had at least parts of it translated for him, very early during, if not before the start of, his own observations. Leeuwenhoek described his findings in a series of letters, beginning in 1673 and continuing over decades, to the Royal Society which duly had them translated into English or Latin - neither of which the author wrote or understood. These observations were in the end perhaps

After a relatively short time, Hooke gave up microscopy because, he said, of weakness of his vision. It seems rather a fitting recompense for his early stimulation of Leeuwenhoek's interest that it was one of the latter's multitudinous letters that encouraged Hooke to turn back to his microscopes in 1677 to confirm the claims in the letter, which he duly did, of finding what were clearly microorganisms in 'pepper-water'.' That it was Leeuwenhoek who made more observations on what we now recognise as micro-organisms is not surprising since, throughout his career, he used only simple microscopes, while Hooke early abandoned the simple microscope in favour of his improved compound model. A simple microscope, consisting of a single small lens of very short focal length, is capable of giving clear images at much higher magnification than the early compound microscope because it is much less subject to the spherical and, particularly, chromatic aberration which was inseparable from the use of multiple lenses in both microscopes and (refracting) telescopes.

It was not until the nineteenth century that microscopes (almost) free from chromatic aberration were made using pairs of lenses with complementary dispersions so that light of effectively all visible wavelengths could be brought to a focus in the same plane. Hooke was perfectly well aware that small single lenses of high radius of curvature, and thus short focal length, were able to produce sharp images at much higher magnification than he could achieve with his compound microscope. Yet he found them so inconvenient to use that after considerable experiment he abandoned them, but not 


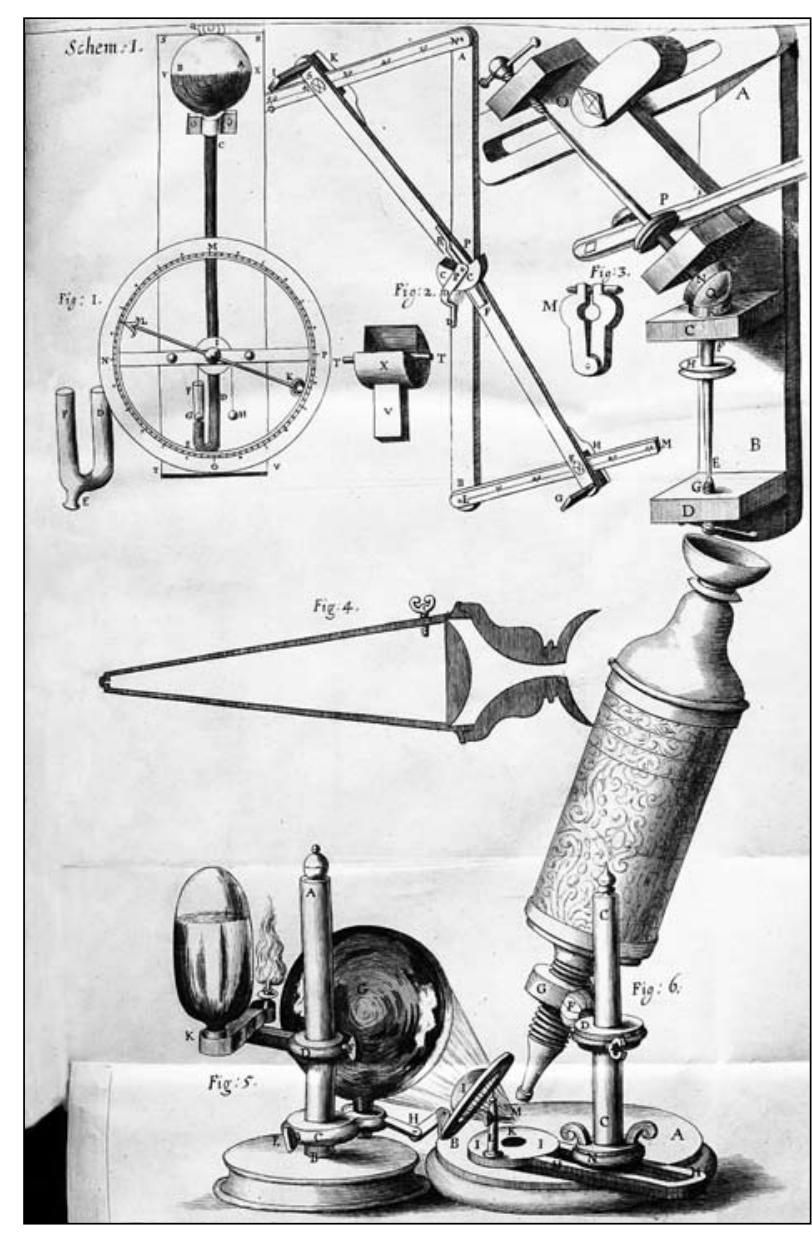

FIGURE I The first engraved fold-out plate showing a number of instruments.

Fig. I: Barometer with pointer driven by float and indicating on dial.

Fig. 2: Device to measure the refraction of light by liquids. Fig. 3: Lens grinding machine.

Fig. 4: Improved two-lens microscope using a water-filled cone. Fig. 5 and Fig. 6: Hooke's compound microscope with its illumination system containing a brine-filled sphere and a plano-convex lens to form a condenser and a new adjustable specimen holder - see Figure 3 for more details.

before he had invented an improved model using a very short focal length lens mounted at one end of a waterfilled cone (Figure I).

Although the title page of Micrographia says the book is devoted to 'some physiological observations of minute bodies made by magnifying glasses with observations and inquiries thereupon', microscopic observations represent only part of its content of new discoveries, instruments and devices. As well as the improved microscope, a hygrometer (Figure 2) to measure the humidity of the air made from the beards of grains of wild oats and a new system for illuminating the specimens (Figure 3), Hooke describes a new type of barometer which indicates atmospheric pressure with a pointer and dial, a new machine for grinding lenses much more easily and accurately and an apparatus for studying the refraction of light by solutions of varying solute concentration and so

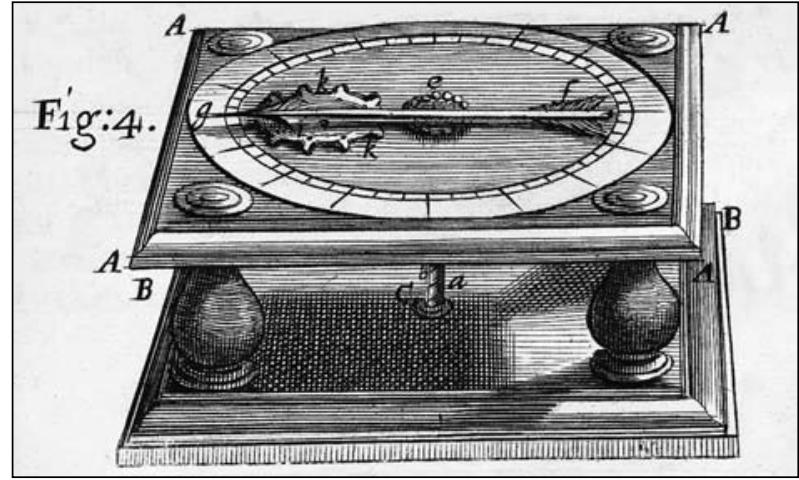

FIGURE 2 Hooke's hygrometer made from the beards of grains of wild oats (from Micrographia, I665, Schema XV). The lower end of the oat beard is attached to the base (a) and its upper end (e) is fixed to the very light pointer ( $\mathrm{f} g$ ). The beard unwinds in humid air rotating the pointer; the little vellum toothed plate $(\mathrm{k} \mathrm{k})$ is moved one tooth at a time by a pin below the pointer and so counts the number of complete revolutions of the pointer.

refractive index. The latter apparatus and the experiments with it were a model for differential refraction at various heights in the atmosphere due to differing air density.

From these observations Hooke was able to set out an explanation for the apparent increase in size of the sun and moon as they approach the horizon. He was very interested in the atmosphere and its properties, having worked with Boyle - his mentor as well as his friend - on the improvement of the 'air-pump' (a vacuum pump) and taken part in many of Boyle's famous experiments with this device. In Micrographia Hooke recounts that, using his improved barometer 'by an Instrument I contriv'd to shew all the minute variations in the pressure of the Air; by which I constantly find, that before, and during the time of rainy weather, the pressure of the Air is less, and in dry weather, ... it is much more,' as succeeding generations of weather forecasters have confirmed.

The College Library has copies of the Micrographia of both 1665 and 1667; the two dates may suggest that there were two editions. However, this is not so; both were printed from the same typesetting as can be seen by careful comparison of the pages, and the text in both is identical. They differ in the title pages and in some details of the engraved plates and so are different issues of the same - the only - edition. The 1665 title page is printed in red and black (the dense black words in the monochrome image on the first page of this article are red in the original); in the 1667 issue all the letterpress is black. Both issues have an image of the Royal Society's arms printed from an engraved copper plate. This is somewhat unusual; unlike woodblocks which can be set up in the forme with metal type and their image printed along with the letterpress in the 'common' hand press, engraved plates must be printed in the quite different 'rolling press' so, if letterpress and a copperplate image are to appear on the same page, the parent sheet must pass (damp) through 


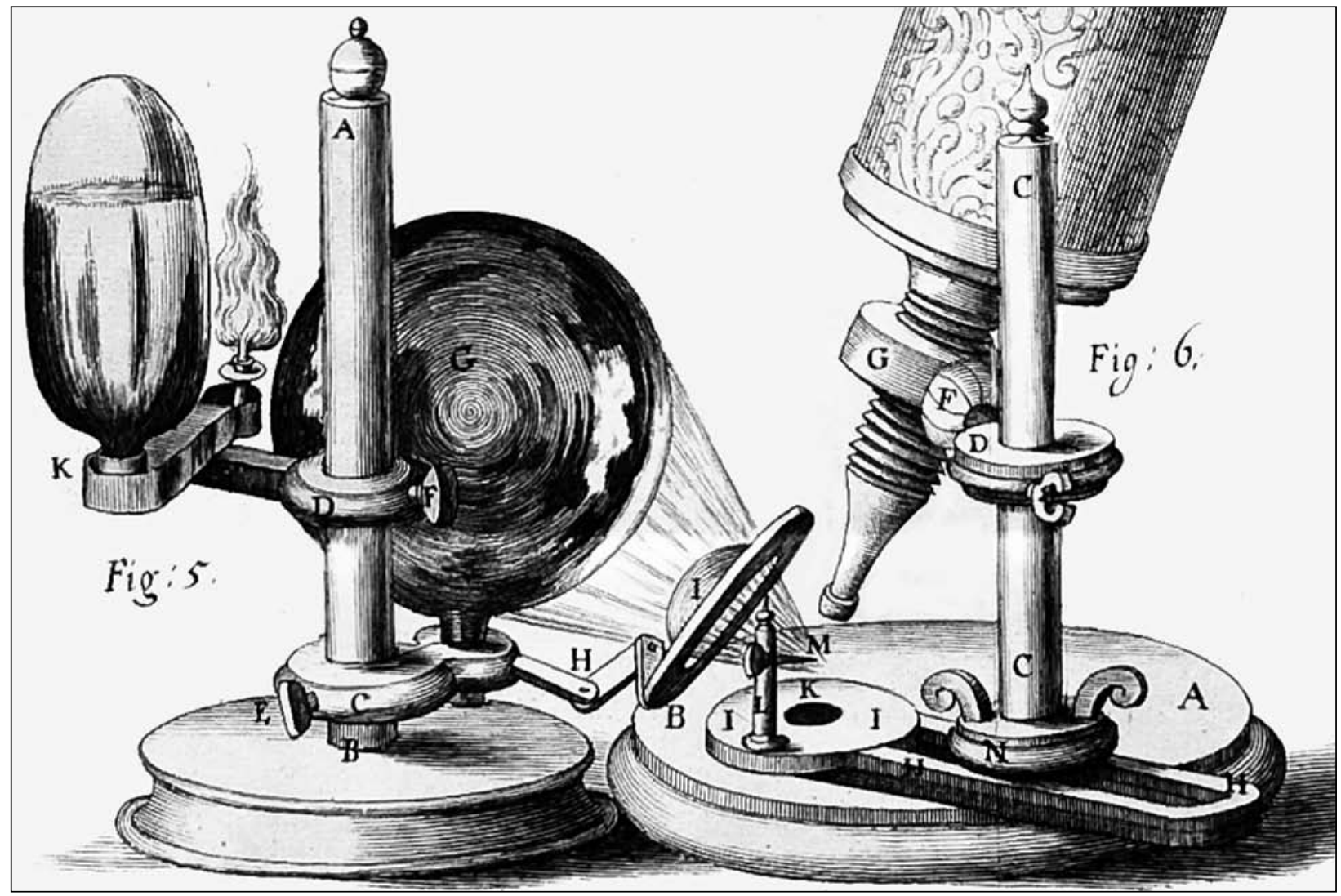

FIGURE 3 Enlarged view from the first engraved fold-out plate of Hooke's new arrangements for artificial illumination of the specimen under the compound microscope and of the adjustable specimen holder. Lamp on pivoted arm (Fig. 5, K); sphere (Fig. 5, G) filled with brine to collect and condense light on to the plano-convex lens (Fig. 6, uppermost I) mounted on a universal jointed system and focusing collected light on to the specimen held at $M$ in the adjustable holder formed by the pillar (L) mounted on the rotating plate (Fig. 6, $\mathrm{K}$ in centre) attached to the slide ( $\mathrm{H} \mathrm{H}$ on the right), which is clamped by a wing nut (N).

the two presses. This leads to problems of register (keeping the relation between image and letterpress correct) and was therefore rarely used after some early experiments.

Now, printing in red and black on the same page also needs two passes (through the common press this time) and, again, it is difficult to keep the correct register. In fact, in the eighteenth century, one of the principal advantages ascribed to the new 'titling' typefaces was that they removed the need to print in two colours for emphasis on title pages. So, our 1665 title page made three passes through the press, through the common press once for the red and once for the black letterpress and through the rolling press once for the copperplate. The result here is reasonably good, although not perfect; we have other seventeenth-century works in which the register of copperplate and letterpress is considerably worse. The expensive and often unsatisfactory combination of copperplate and letterpress was largely

\section{REFERENCES}

I Gest H. The discovery of microorganisms by Robert Hooke and Antoni van Leeuwenhoek, Fellows of the Royal Society. Notes Rec $R$ Soc London 2004; 58: I87-20I. doi:I0.1098/rsnr.2004.0055

2 Robinson T. Some observations on the French macreuse, and the Scotch bernacle; together with a continuation of the account of abandoned before the end of the seventeenth century. Whether the simpler monochrome title page of the I 667 issue was intended to save cost I do not know.

Our copy of the 1667 issue contains many annotations of the text which a manuscript note on the title page attributes to Tancred Robinson (1657/8-1748), Fellow of the Royal College of Physicians of London and of the Royal Society, who visited France with Hans Sloane and was later Physician in Ordinary to George I by whom he was knighted. Robinson was interested in natural history and his correspondence with John Ray was published in the Philosophical Transactions of the Royal Society. In these letters ${ }^{2,3}$ Robinson and Ray discuss the scoter (macreuse) and the Barnacle goose about which Sir Robert Sibbald, founder of the College Library, had written extensively in his Scotia Illustrata of I684.

IML Donaldson, Honorary Librarian, RCPE (email: i.m.l.d@ed.ac.uk)

boyling, and other fountains. Phil Trans 1685; 15:1036-40; doi:I0.1098/rstl. I685.0042

3 Ray J.A letter from Mr. Ray, Fellow of the R. S. to Dr. Robinson; concerning the French macreuse. Phil Trans 1685; 15:1041-44; doi:I0.1098/rstl.I685.0043 